\title{
SARCOIDOSIS OF THE SIGMOID COLON
}

\author{
A. Gourevitch, M.C., M.Ch., F.R.C.S. \\ I. J. Cunningham, B.Sc., M.B. Ch.B., M.R.C.S., L.R.C.P. \\ Queen Elizabeth Hospital, Birmingham.
}

Sarcoidosis is a strange disease of protean manifestations and unknown aetiology, first described as a skin lesion by Boeck in 1899 . Though it may involve any tissue in the body (Longcope, r94I), it is usually associated with lesions of skin, lymph nodes, lungs or salivary glands.

Its accidental discovery in other tissues or regions of the body, not usually associated in the mind of the clinician with the disease, may come as a surprise and lead to tragic results as in the case about to be described.

Raven (i949), in a review of the surgical manifestations of sarcoidosis, includes reports of cases involving the alimentary tract, but the literature on this subject is scanty. For this reason it is deemed appropriate to include a brief review of the literature on sarcoid lesions of the alimentary tract.

To our knowledge only one other case of sarcoidosis involving the colon has been reported (Raven, 1949): In view of this we feel the following case is worthy of note.

\section{Case Report}

A male, Mr. E., aged fifty-three, a radioengineer was admitted on December 19, 1957, for investigation of persistent diarrhoea and weight loss. He had developed diarrhoea eight months previously, which had increased in severity until he was passing up to a dozen loose motions a day, and had difficulty in retaining the contents of the rectum. The motion consisted mainly of mucus, occasionally streaked with blood, but very little faecal material. Previously his bowel habit had been two soft, formed motions a day. Latterly there had been a good deal of tenesmus, and pain on defaecation. The latter was found on examination to be due to a fissure-in-ano. During this illness, he had lost two stone in weight.

\section{Past History}

In 1954 he had a short-lived episode of diarrhoea. Barium enema, at this time, was reported as normal, and a sigmoidoscopy revealed a red, inflamed mucous membrane.

\section{On Examination}

The patient was an ill-looking man, with signs of recent weight loss, and a slightly cyanotic tinge. B/P 120/80. No cardiac abnormality. Chest expansion was poor, with numerous rhonci at lung bases. Abdominal examination on the first occasion was normal. Later examination revealed a mobile swelling in the left iliac fossa in the position of the sigmoid colon. Rectal examination was impossible due to the intense anal spasm caused by a large fissure-in-ano.

\section{Special Investigations}

(r) $\mathrm{Hb}=16$ g. per cent. W.B.C. 7,500 c.mm.

(2) Occult blood tests negative.

(3) Stool culture negative.

(4) Urine-no abnormality.

(5) Chest X-ray showed partial atelectasis of the right lower lobe, suggesting an old inflammatory lesion.

(6) Barium enema showed an intussusception of the lower portion of the descending colon into the sigmoid loop, the cause of which would appear to be an annular carcinoma. It was impossible to reduce the intussusception completely.'

The history, clinical findings and barium enema result appeared to confirm the provisional diagnosis of carcinoma of the sigmoid colon, so a laparotomy was performed.

\section{Operation, December 30, 1957}

Under general anaesthesia the abdomen was opened through a lower left paramedian incision. A thickened, indurated, inflamed loop of sigmoid colon was found. The inflammatory process involved the bowel wall and the pericolic tissues as in diverticulitis. There was no evidence of an intussusception or carcinoma of the sigmoid colon, or any other lesion of the large or small intestines. The findings were consistent with diverticulitis, 
though it was noted that a row of diverticula on the anti-mesenteric border of the bowel was apparently not inflamed. The affected loop of sigmoid colon was resected and a primary end-to-end anastomosis performed. On inspection of the anastomosis, pulsating vessels were observed immediately adjacent to it.

Post-operative progress was never satisfactory. After operation the patient began to pass green, fluid motions several times a day. A diagnosis of probable staphylococcal entero-colitis was made. Stool culture revealed only moderate excess of coagulase negative staphylococci sensitive only to chloromycetin. Despite gastric intubation, intravenous fluid therapy and treatment with chloromycetin, his condition deteriorated. On the fourth day post-operatively he developed abdominal pain, and the signs of general peritonitis.

\section{Operation, Fanuary 4, 1958}

The abdomen was re-opened through the previous incision. An extensive general peritonitis with a large amount of offensive free fluid was found, due to a complete disruption of the original anastomosis, which showed no signs of healing. The affected loop was mobilized, the distal end closed, and the proximal loop brought out as a colostomy.

Following this operation his condition remained poor, and he died 36 hours later from toxaemia and peripheral circulatory failure. Post-mortem, unfortunately, was not performed.

\section{Pathology Report}

' Gross: A resected portion of sigmoid colon. The bowel mucosa is intact and there is diverticulosis. Microscopic: The submucosa and to a greater extent the pericolic tissues show follicular structure with central epitheloid cells and giant cells and surrounding lymphocytes and fibroblasts. The giant cells show asteroid bodies and vacuoles, and the nuclei are random throughout the cytoplasm in contra-distinction to the tuberculous giant cells; there is no central caseation in the follicles and Z.N. stains fail to reveal tubercle bacilli. The appearances are those of sarcoidosis of the sigmoid colon.'

\section{Discussion}

The occurrence of sarcoidosis in the alimentary tract is unusual and relatively few cases have been reported. Only one case involving the oesophagus has been reported (Kerley, I950).

Several cases of sarcoidosis of the stomach are reported, and these are reviewed by Allen, Butler and Jefferson (1956). In a careful analysis of the 22 cases reported, they exclude eight cases as the evidence to support a diagnosis of sarcoidosis is insufficient. The remaining 14 cases they divide into three groups. In the first group they include those patients with a clinical picture of pyloric stenosis, and the barium meal showed a narrowing of the gastric lumen, loss of the normal mucosal pattern and absence of peristalsis. In fact they presented the features of a scirrhous carcinoma. The second group includes those patients who had the symptoms and radiological evidence of an ulcer, for which gastrectomy was performed, and histological examination showed the features of sarcoidosis. The ulceration of the mucosa in these cases, probably was secondary to infiltration of the submucosa and mucosa by the sarcoid tissue. In the last group were three cases where sarcoidosis was an accidental finding. In two cases the diagnosis was made following gastrectomy for haematemesis, and in the third case the changes in the stomach were observed at post-mortem in a patient who died from congestive cardiac failure.

Few cases of sarcoidosis involving the small intestine have been reported. Watson et al. (1945) report two cases of apparently localized sarcoidosis involving the small intestine. They comment ono the similarity between the radiological features of regional ileitis and sarcoidosis, but stress certain of the features characteristic of sarcoidosis, sucto as multiple polypoidal filling defects. Involvement of the small intestine has also been observed in few cases of systemic sarcoidosis (Bernstein et al. 1929; Cotter, 1939) and more recently Cowdel (1954) has reported a case in a young girl of fifteen.

So far as we have been able to ascertain only one other case of sarcoidosis involving the large bowel has been reported (Raven, 1949). The case reported was a man, aged fifty-three, admitted for investigation of epigastric pain, intermittent attacks of diarrhoea, anorexia and loss of weight. Clinically there was a palpable mass in the region of the ascending colon. Barium enema showed a stricture in the ascending colon, and the appearances were suggestive of a neoplasm. At operation a right hemicolectomy with an ileotransverse colostomy was performed, and the patient made an uninterrupted recovery. Microscopy of the resected bowel and related lymph nodes showed the histological appearances of sarcoidosis.

The surgical implications of this type of lesion are important. The symptomatology and the radiological appearances of the colon in our case, and Raven's case, were in favour of a pre-operative diagnosis of carcinoma of the colon. In the case reported by Raven, the appearances at operation supported the diagnosis of carcinoma, so a radical excision was performed. In our case, the lesion at operation simulated diverticulitis of the sigmoid 
colon, so a local excision with primary anastomosis was performed, with the results described.

The complete absence of healing at the suture line is of interest. Watson et al. (1945) describe a case of sarcoidosis of the small intestine in which it was recognized that the resection was carried out through involved bowel at both ends but an endto-end anastomosis was performed and the postoperative progress was uneventful. However, on a priori grounds it is to be expected that the complex process of healing with cellular infiltration and migration would be disturbed by the fibrosis of the tissues associated with the sarcoid infiltration.

\section{Summary}

I. A case of sarcoidosis of the sigmoid colon is reported.

2. The problem of diagnosis and treatment are discussed, together with a short review of the literature on sarcoidosis of the alimentary tract.

\section{Acknowledgments}

We wish to thank Dr. K. Thornton for the pathological report.

\section{BIBLIOGRAPHY}

ALLEN, E. H., BUTLER, J. C., and JEFFERSON, K. (1956), Brit. F. Radiol., 29, 56.

BERNSTEIN, N., KONZLEMANN, F. W., and SIDLICK, D. M. (1929), Arch. Intern. Med., $44,721$.

COTTER, E. F. (1939), Ibid., 64, 286.

COWDELL, R. H. (1954), Quart. F. Med., 89, 29.

GORE, I., and MCCARTHY, A. M. (1944), Surgery, 16, 865.

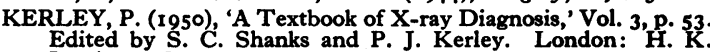
Lewis, 1958 .

LONGCOPE, W. T. (1941), F. Amer. Med. Ass., 117, 1321.

RAVEN, R. W. (1949), Ann. Roy. Coll. Surg., 5, 3.

WATSON, C. J., RIGLER, L. G., WANGENSTEEN, O. H., and MCCARTNEY, J. S. (1945), Gastroenterology, 4, 30.

\title{
SARCOIDOSIS
}

(Postgraduate Medical Journal, May 1958)

Price 6s. 6d. post free

\section{INTRODUCTION}

THE EARLY DIAGNOSIS OF SARCOIDOSIS

D. Geraint James, M.D., M.R.C.P.

THE HISTORICAL ASPECTS OF SARCOIDOSIS

Professor Niels Danbolt, M.D.

THE PATHOLOGY OF SARCOIDOSIS

A. D. Thomas, M.A., M.D., M.R.C.P.

THE AETIOLOGY OF SARCOIDOSIS

Louis E. Siltzbach, M.D.
THE NERVOUS SYSTEM IN SARCOIDOSIS

Michael Jefferson, D.M., M.A., B.Sc., M.R.C.P.

BERYLLIUM DISEASE

I. B. Sneddon, M.B., Ch.B., F.R.C.P.

\section{INTRATHORACIC SARCOIDOSIS}

Kenneth M. Citron, M.D., M.R.C.P., M.R.C.S.

\section{CUTANEOUS SARCOIDOSIS}

Gordon B. Mitchell-Heggs, M.D., F.R.C.P., and Michael Feiwel, M.B., Ch.B., M.R.C.P.

Published by

THE FELLOWSHIP OF POSTGRADUATE MEDICINE

\author{
60, Portland Place, London, W.1
}

